\title{
oipA "on" status of Helicobacter pylori is associated with gastric cancer in North- Eastern Brazil
}

\author{
Lúcia Libanez Bessa Campelo Braga', Maria Helane Rocha Batista², Orleâncio Gomes Ripardo de Azevedo², \\ Kassiane Cristine da Silva Costa ${ }^{2}$, Adriana Dias Gomes ${ }^{3}$, Gifone Aguiar Rocha ${ }^{3}$ and \\ Dulciene Maria Magalhães Queiroz ${ }^{3^{*}}$ (D)
}

\begin{abstract}
Background: Although, outer membrane protein OipA of Helicobacter pylori has been associated with gastric mucosal damage and gastroduodenal diseases, studies evaluating gastric cancer patients are scarce. We investigated whether the functional oipA "on" status was associated with gastric cancer in the North-eastern Brazil, region with high prevalence of gastric cancer.

Methods: We included samples from 95 H. pylori positive subjects (23 patients with gastritis, 24 with gastric cancer, 32 first-degree relatives of gastric cancer patients and 16 children). oipA was assayed by polymerase chain reaction (PCR) and DNA sequencing. cagA and vacA status were evaluated by PCR.

Results: Overall $81.1 \%$ of the $H$. pylori strains had functional oipA. In adults, the oipA "on" status (OR=9.20; $95 \% \mathrm{Cl}=1.45-58.48, P=0.02)$ and increasing age $(\mathrm{OR}=1.08 ; 95 \% \mathrm{Cl}=1.03-1.14 ; P=0.003)$ were independently associated with gastric cancer in a logistic model. The oipA "on" status (OR $=14.75 ; 95 \% \mathrm{Cl}$ : 2.53-86.13, $P=0.003)$ was also associated with first-degree relatives of gastric cancer patients when compared with gastritis. The frequency of oipA "on" status did not differ between children and adults $(P=0.87)$. The oipA "on" status was significantly correlated with the presence of cagA and vacA s1 $\mathrm{m} 1$.
\end{abstract}

Conclusion: oipA "on" status was independently associated with gastric cancer and first-degree relatives of gastric cancer patients in North-eastern Brazil.

Keywords: Helicobacter pylori, oipA, cagA, vacA, Gastric cancer

\section{Background}

Gastric cancer is the fifth most common cancer and the third leading cause of mortality among men and the fifth among women, with more than 700,000 deaths per year worldwide [1]. The malignancy is more frequently observed in developing than in developed countries $[1,2]$. In Brazil, gastric cancer is the fourth most common malignancy among men and the sixth among women, excluding skin tumors [3]. In the North-east Brazil, one of the least developed regions of the country, gastric cancer

\footnotetext{
* Correspondence: dqueiroz@medicina.ufmg.br

${ }^{3}$ Laboratory of Research in Bacteriology, Faculdade de Medicina,

Universidade Federal de Minas Gerais, Av. Alfredo Balena, 190 - Sala 216,

Belo Horizonte CEP: 30130-100, Brazil

Full list of author information is available at the end of the article
}

is the second and the sixth most common tumor among males and females, respectively [3].

Helicobacter pylori is a well-recognized bacterium that chronically infects the stomach of approximately half of the world's population being more prevalent in developing countries. Chronic H. pylori infection is considered the strongest risk factor for distal gastric adenocarcinoma [4]. The prevalence of $H$. pylori infection is estimated in approximately $90 \%$ of gastric cancer patients $[1,5]$. In addition, the bacterium is associated with low grade B-cell MALT gastric lymphoma [6] and significantly increases the risk of development of peptic ulcer disease [7]. The mechanisms by which the infection progresses to the associated diseases are not completely known and depend on

(c) The Author(s). 2019 Open Access This article is distributed under the terms of the Creative Commons Attribution 4.0 International License (http://creativecommons.org/licenses/by/4.0/), which permits unrestricted use, distribution, and reproduction in any medium, provided you give appropriate credit to the original author(s) and the source, provide a link to the Creative Commons license, and indicate if changes were made. The Creative Commons Public Domain Dedication waiver (http://creativecommons.org/publicdomain/zero/1.0/) applies to the data made available in this article, unless otherwise stated. 
the relationship among host genetics, environmental and bacterial virulence factors [8].

Among the bacterial virulence genes, cag-PAI (cytotoxin associated gene pathogenicity island), containing several genes that trigger abnormal cellular signals, is considered the most important risk factor for $H$. pylor$i$-associated gastric cancer. $v a c \mathrm{~A}$ virulence gene that encodes a vacuolating cytotoxin A (VacA) is also associated with $H$. pylori severe diseases; gastric cancer and duodenal ulcer [9].

Another group of putative virulence genes belongs to the H. pylori outer membrane proteins. OipA (outer inflammatory protein), one member of this large protein family, is encoded by oipA gene. The expression of the OipA is predicted to be regulated by a slipped strand mispairing system based on the number of CT dinucleotide repeats in the $5^{\prime}$ signal peptide coding region of the gene with "on" meaning that oipA is functional and "off" when the gene is non-functional [10]. oipA functional status is involved in the bacterial adherence to the gastric epithelial cells and in mucosal inflammation [11]. Moreover, the protein has been associated with interleukin (IL)-8 induction, mucosal damage and with duodenal ulcer [11]. A study evaluating Colombian patients demonstrated association of OipA with gastric cancer [12]. However, there are geographic variations. Studies from Italy and Netherlands have not demonstrated association between oipA and H. pylori clinical outcomes [13, 14]. To date, there are no studies evaluating the oipA functional status and risk of gastric cancer in Brazil. Moreover, it has to be emphasized that first-degree relatives of gastric cancer patients, who are thought to be at increased risk of gastric cancer, have not been evaluated yet. Therefore, the aim of the present study is to evaluate whether the functional oipA "on" status is associated with gastric cancer and first-degree relatives of gastric cancer patients in North-east Brazil, characterized by both high prevalence of gastric cancer and H. pylori infection.

\section{Methods}

\section{Patients}

The study was approved by the Ethics Committee of the University of Ceará and informed written consent was obtained from all adults and children (whenever possible) and their legal guardians.

We included 95 subjects infected with $H$. pylori strains: 23 with gastritis (13 females; mean age $45.6 \pm 13.6$ years; range $19-65$ years) and 24 with non-cardia gastric cancer (9 females; mean age, $61.2 \pm 15.4$ years; range $36-84$ years) who underwent upper endoscopy for evaluation of dyspeptic symptoms or underwent gastric surgery to remove gastric carcinoma at the University Hospital Walter Cantídio, Fortaleza, Brazil. Thirty-two H. pylori-positive first-degree relatives of gastric cancer patients ( 25 females; mean age $44.4 \pm 10.2$; range $19-60$ years) attending the Walter Cantídio Hospital to be submitted to endoscopic screening for gastric cancer were randomly selected. DNA was also obtained from gastric juice/mucus by string test [15] from 16 asymptomatic children (6 girls; mean age, $12.6 \pm 3.2$ years; range $8-18$ years) who had previously participated in a $H$. pylori epidemiological study in Parque Universitário, an urban community in Fortaleza, Brazil, from whom the $H$. pylori status was determined by ${ }^{13} \mathrm{C}$-urea breath test according to the protocol previously validated for the Brazilian population [16]. In the group of gastritis patients and first-degree relatives of gastric cancer patients, endoscopic biopsy samples were obtained from the antral and oxyntic gastric mucosa for histological, microbiological and DNA evaluation. Antral and oxyntic biopsy specimens were fixed in $10 \%$ formalin and embedded in paraffin wax, and 4- $\mu \mathrm{m}$-thick histological sections were stained with carbolfuchsin for $H$. pylori investigation [17] and hematoxylin and eosin for histological analysis according to the updated Sydney System [18]. In the group of gastric cancer patients, the fragments were obtained from the stomach removed by gastrectomy after opening it along the greater curvature within $1 \mathrm{~h}$ of resection. The tumor was classified according to Laurén classification [19]. Gastric fragments were obtained from the gastric cancer patients $(5 \mathrm{~cm}$ from the tumor) for microbiological, histological and DNA evaluation. Adults and children who had taken antimicrobials 30 days before and/ or pump proton inhibitor 2 weeks before the procedures were excluded from the study.

\section{DNA extraction}

The DNA was extracted using QIAmp Kit (QIAGEN, Hilden, Germany) according to the manufacturer's recommendations. The DNA concentration was determined by spectrophotometry using NanoDrop 2000 (Thermo Scientific, Wilmington, NC) and stored at $-20{ }^{\circ} \mathrm{C}$ until use.

\section{oipA genotyping and sequencing}

The oipA gene was amplified by using the primers and thermo cycling conditions previously described by Yamaoka et al. [10]. Ninety-five H. pylori oipA-positive strains were PCR sequenced in order to assess the oip A status. The PCR products were purified using Wizard $\mathrm{SV} \mathrm{Gel}^{\circ}$ and PCR Clean-up System ${ }^{\circ}$ (Promega, Madison, $\mathrm{MI})$, and then the purified products were sequenced using the Big Dye Terminator kit version 3.1 Cycle Se-

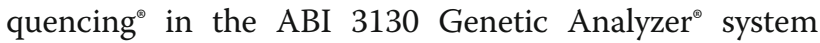
(Applied Biosystems, Foster City, CA). The nucleotide sequences were analyzed using CAP3 software and the BLAST system (http://www.ncbi.nlm.nih.gov). 


\section{cag $A$ and vacA genotyping}

The cagA gene was amplified as previously described [20]. PCR amplification of the vacA signal sequence and mid-region was performed according to Ashour et al. [21], by using the oligonucleotide primers described by Atherton et al. [22]. The LPB $1010 \mathrm{H}$. pylori strain (s1 $\mathrm{m} 1$ and cagA-positive) was used as a positive control. The standard, Tx30A H. pylori strain (s2 m2 vacA genotype and cagA-negative) and distilled water were both used as negative controls.

\section{Statistical analysis}

The association of each variable, including age, gender and oipA "on" status with the $H$. pylori-associated diseases (dependent variable) was tested in univariate analysis. All variables with a $P$-value of 0.20 or less were included in the full model of logistic regression. Odds ratio (OR) and 95\% confidence interval (CI) were used as an estimate of the risk. The Hosmer-Lemeshow goodness-of-fit test was used to evaluate the fit of models. Correlations were evaluated by Pearson or Spearman's correlations. Data were analysed with the software SPSS for Windows, v. 17.0 (SPSS Inc., Chicago, IL). The level of significance was set at $P \leq 0.05$.

\section{Results}

\section{oipA status and demographic data}

The H. pylori-specific oipA gene was successfully sequenced in all evaluated samples.

Overall, $81.1 \%$ (77/95) of the $H$. pylori strains sequenced had oipA "on" status and 18.9\% (18/95) had status "off". No difference was observed between the mean age of patients infected with oipA "on" status (44.29 SD
$19.5 \mathrm{yrs})$ and age of those infected with oipA "off" (40.67 SD 20.89 yrs $)$ of $H$. pylori $(P=0.48)$.

The number of $\mathrm{CT}$ repeat patterns ranged from five to nine (Table 1$)$. The 6 CT pattern $[76.6 \%$ (59/77)] was the most frequent $\mathrm{CT}$ dinucleotide repeats found among the oipA "on" status. The other oipA "on" status observed were: $1+4$ CT $[19.5 \%(15 / 77)]$ and 9 CT [3.9\% (3/77)] repeat patterns. Among the oipA "off" status $(n=18)$, the following CT repeat patterns were found: 5 CTs $(n=4 / 22.2 \%), 7$ CT ( $n=11 / 61.1 \%), 8 \mathrm{CT}(n=2 / 11.1 \%), 9$ CT $(n=1 / 5.6 \%)$. The CT pattern frequency according to the different $H$. pylori positive subjects are shown in Table 2.

The functional "on" status was observed in $91.7 \%$ $(22 / 24)$ of the adult patients with gastric cancer, in $60.9 \%(14 / 23)$ of the patients with gastritis and in $93.8 \%(30 / 32)$ of the first-degree relatives of gastric cancer patients (Fig. 1). Among children, the oipA "on" status was found in $68.8 \%(11 / 16)$ of the $H$. pylori strains, without significant difference from that of the adults with gastritis $(P=0.87$; OR $=1.41 ; 95 \% \mathrm{CI}=0.37-5.55$; two-tailed $X^{2}$-test).

\section{Association between oipA "on" status and gastric cancer}

In order to identify variables independently associated with gastric cancer compared with gastritis, the data were analyzed in logistic regression model. In the univariate analysis, the oipA "on" status and increasing age were selected. In the multivariate analysis, the oipA "on" status and increasing age remained independently associated with gastric cancer (Table 3).

No difference was observed in the oipA "on" or "off" status and the tumor type. oipA "on" status was observed in $17 / 18$ and in 5/6 intestinal and diffuse type tumor, respectively.

Table 1 Signal-sequence coding region of H. pylori oipA observed in a Brazilian population

\begin{tabular}{|c|c|c|}
\hline Sequence & CT repeats/Number & Gene status \\
\hline ATGAAAAAAGCYCTCTTACTAACTCTCTCTCTCT-- & 6 & on \\
\hline 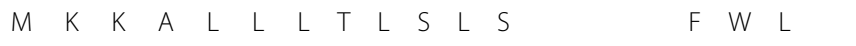 & & \\
\hline ATGAAAAAAGCTCTCTTACTAACTITCTCTCTCT---2--CGTITTGGTC & $1+4$ & on \\
\hline 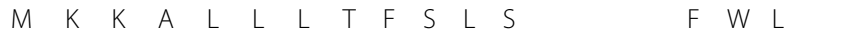 & & \\
\hline ATGAAAAAAGCYCTCTTACTAACTCTCTCTCTCTCTCTCT------GTTTTGGCTC & 9 & on \\
\hline$M \quad K \quad K \quad K \quad A \quad L \quad L \quad L \quad T \quad L \quad S \quad L \quad S \quad L \quad S$ & & \\
\hline ATGAAAAAAGCYCTCTTACTAACTCTCTCTCT----1-2-1--- CGTTTGGCT & 5 & off \\
\hline 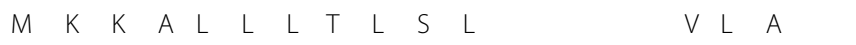 & & \\
\hline ATGAAAAAAGCYCTCTTACTAACTCTCTCTCTCTCT-----a--- CGTTTTGGC & 7 & off \\
\hline 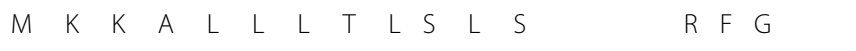 & & \\
\hline ATGAAAAAAGCYCTCTTACTAACTCTCTCTCTCTCTCT--------CGTTTTGGCT & 8 & off \\
\hline 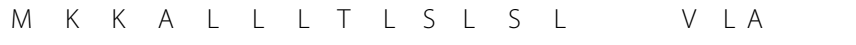 & & \\
\hline ATGAAAAAAACYCTCTTACTCTCTCTCTCTCTCTCT--_-_--CGTTTTGGC & 9 & off \\
\hline 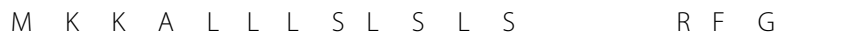 & & \\
\hline
\end{tabular}


Table 2 Frequency of oipA "on" status in subjects $(n=118)$ with H. pylori associated diseases

\begin{tabular}{|c|c|c|c|c|c|}
\hline $\mathrm{n}(\mathrm{CT})$ & $\begin{array}{l}\text { CG (23) } \\
\text { n (\%) }\end{array}$ & $\begin{array}{l}\text { GC (24) } \\
\text { n (\%) }\end{array}$ & $\begin{array}{l}\text { GC rel (32) } \\
\text { n (\%) }\end{array}$ & $\begin{array}{l}\text { Children (16) } \\
\text { n (\%) }\end{array}$ & $\begin{array}{l}\text { Total (95) } \\
\text { n (\%) }\end{array}$ \\
\hline \multicolumn{6}{|l|}{ On } \\
\hline 6 & $13(56.5)$ & $18(75.0)$ & 21 (65.6) & 07 (43.8) & $59(62.1)$ \\
\hline $1+4$ & $01(4.3)$ & $03(12.5)$ & 09 (28.1) & $02(12.5)$ & 15 (15.7) \\
\hline 9 & - & $01(4.2)$ & - & 02 (12.5) & $03(3.2)$ \\
\hline Total & $14(60.9)$ & $22(91.7)$ & 30 (93.8) & $11(68.8)$ & 77 (81.1) \\
\hline \multicolumn{6}{|l|}{ Off } \\
\hline 7 & $06(26.1)$ & $02(8.3)$ & & 03 (18.7) & 11 (11.6) \\
\hline 8 & $01(4.3)$ & - & $01(3.1)$ & - & $02(2.1)$ \\
\hline 5 & $02(8.7)$ & - & $01(3.1)$ & $01(6.3)$ & $04(4.2)$ \\
\hline 9 & - & - & - & $01(12.5)$ & $01(1.1)$ \\
\hline Total & 09 (39.1) & $02(8.3)$ & $02(6.2)$ & $05(37.5)$ & 18 (18.9) \\
\hline
\end{tabular}

on, gene in frame; $n$, number; $\mathrm{CT}$, cytosine-thymine repeats, off, gene out of frame; $\mathrm{CG}$, chronic gastritis; GC, gastric cancer; GC rel, first-degree relatives of gastric cancer patients

\section{Association between oipA "on" status and first-degree relatives of gastric cancer patients}

Next, we evaluated the variables associated with the first-degree relatives of gastric cancer patients when compared with gastritis patients. In the univariate analysis, in addition to the oipA "on" status and increasing age, the gender was selected. In the multivariate analysis,
oipA "on" status and gender remained associated with first-degree relatives of gastric cancer patients (Table 3).

\section{Comparison of oipA "on" status between gastric cancer and first-degree relatives of gastric cancer}

No significant difference was observed in the frequency of oipA "on" status between gastric cancer and the first-degree relatives of gastric cancer patients $(P=1.0$, two-tailed Fisher's exact test).

\section{Correlation between oipA "on" status and other H. pylori virulent factors}

In the gastritis group, the oipA "on" status was positively correlated with the presence of cagA $(r=0.27, P=0.02)$ and vacA s1 $\mathrm{m} 1 \quad(r=0.30, P=0.01)$, but negatively correlated with the presence of vacA m2 allele $(r=-0.44, P=0.001)$. In the gastric cancer patients, the percentage of simultaneously positive oipA "on" status and cagA was 91.7\% $(r=1, P<0.001)$. High positive correlation was also observed between in frame oip A and s1 $\mathrm{m} 1$ genotype $(r=0.80, P<0.001)$. In respect to the gastric cancer relatives, high percentages were also observed in oip A "on" status and cagA positivity (88.0\%) as well as in oipA "on" status and s1 m1 vacA genotype $(83.3 \%)$.

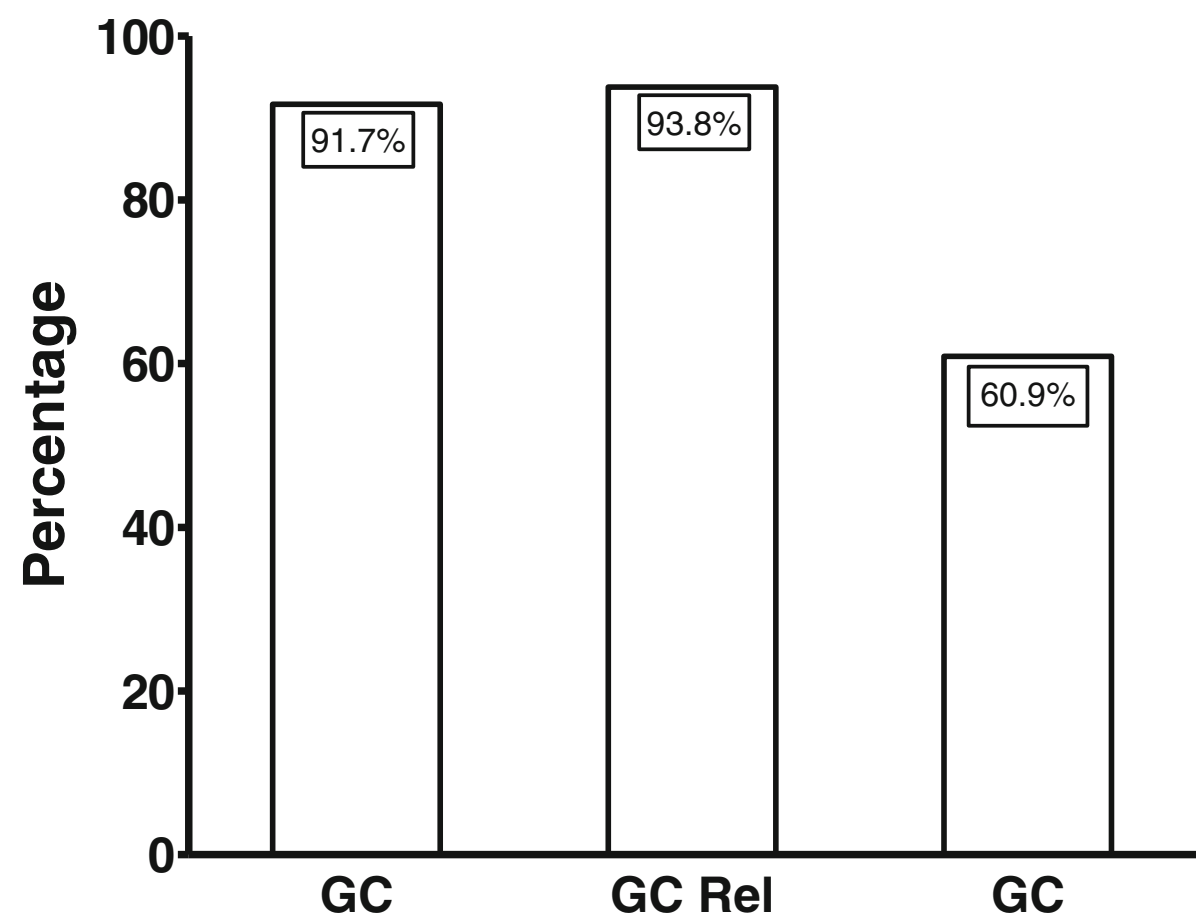

Fig. 1 Frequency of oipA "on" status Helicobacter pylori strains in patients with gastric cancer (GC), first-degree relatives of gastric cancer patients (rel GC) and chronic gastritis (CG) 
Table 3 Logistic regression models including gastric cancer or first-degree relative of gastric cancer patients as variables dependent in comparison with gastritis and oipA, age and gender as independent variables

\begin{tabular}{|c|c|c|c|c|}
\hline \multirow[t]{2}{*}{ Variables } & \multirow{2}{*}{$\begin{array}{l}\text { Univariate } \\
P \text { value }\end{array}$} & \multicolumn{3}{|c|}{ Multivariate } \\
\hline & & $\overline{\mathrm{OR}}$ & $95 \% \mathrm{Cl}$ & $P$ value \\
\hline \multicolumn{5}{|l|}{ Gastric cancer $^{a}$} \\
\hline Increasing age & 0.06 & 1.08 & $1.03-1.14$ & 0.003 \\
\hline Gender & 0.74 & & & \\
\hline oipA + status "on" & 0.013 & 9.20 & $1.45-58.48$ & 0.02 \\
\hline \multicolumn{5}{|l|}{ Relatives of $G C^{b}$} \\
\hline Increasing age & 0.70 & - & - & - \\
\hline Gender & 0.09 & 4.61 & $1.22-17.74$ & 0.02 \\
\hline oipA + status "on" & 0.003 & 14.75 & $2.53-86.13$ & 0.003 \\
\hline
\end{tabular}

+ , positive; OR, odds ratio; $\mathrm{Cl}$, confidence interval; Relatives of GC, first-degree relatives of gastric cancer patients. The Hosmer-Lemeshow tests showed good fitness of the logistic regression model ${ }^{\mathrm{a}}(P=0.46 ; 8$ degrees of freedom; 9 steps) and ${ }^{\mathrm{b}}(P=0.42 ; 8$ degrees of freedom; 9 steps $)$

\section{Association between oipA "on" status and histological gastritis}

The presence of gastritis in the antral and oxyntic mucosa was higher in the first-degree relatives of gastric cancer patients $(11-52.4 \%)$ than in the gastritis patients (3-13.0\%), (a tendency of association; $P=0.08-$ Mantel Haensel two-tailed chi-square test). In the group of gastritis patients, the pattern of the antral gastritis was more frequently mild than moderate/severe (4/9-44.4\% vs. 5/19-26.3\%). Otherwise, because the frequency of oipA "on" status was very high in the group of the first-degree relatives of gastric cancer patients, no association was observed between the presence of functional oipA and the degree of mononuclear and polymorphonuclear cells in the gastric mucosa.

\section{Discussion}

Gastric cancer remains a major healthy problem, especially in developing countries. Unfavorable outcome of H. pylori infection to gastric cancer depends on genetics, environmental factors and virulence markers of the bacterium. Host genetic association has been demonstrated by the intra-familiar increased risk of gastric cancer. Notably, factors are emerging as key determinants. Among them, it has to be emphasized polymorphisms in genes involved in the adaptive immune response such as the IL-1 $\beta$ cytokine [23] and in members of the host's innate immune response, Toll-like receptor-4 (TLR-4), which are associated with increased risk of gastric cancer [24]. In both cases the gastritis may progress to chronic atrophic gastritis, multifocal intestinal metaplasia and increased risk of gastric cancer. Unhealthy dietary patterns rich in starchy, meat, fat and high salt concentration contribute to gastric cancer development. In addition to well established association between gastric cancer and
cagA and vacA here we confirmed functional oipA "on" status as a risk of gastric cancer and demonstrated that it is associated with first-degree relatives of gastric cancer patients. Furthermore, this study is the first in Brazil to evaluate the prevalence of $H$. pylori oipA "on" status in both adults and children. Overall the oipA "on" status was found in most of the evaluated strains (81.1\%), similarly to that observed in Bulgaria (81.0\%) [25], Colombia (79.3\%) [13] and Venezuela (83.0\%) [26]. It has to be emphasized that the prevalence of status "on" is very high in Asian countries such as Japan (100\%) [27] and Malaysia/ Singapore (> 85.0\%) [28]. Otherwise, studies from developed Western countries such as Germany (59.0\%) [29] and North Italy (60\%) [30] demonstrated that the prevalence of oipA "on" status is lower than that observed in the current study. In children, the frequency of oipA "on" status was higher in the $H$. pylori strains from Brazil than in those from Portugal (49.6\%) [31] and USA (45.9\%) [32]. This high frequency of oipA "on" status observed in the children is in agreement with high prevalence of other $H$. pylori risk factors we have previously observed in children from the same population [15]. Taking together, the differences among countries point to regional differences that may be linked to differences in the social levels, genetics and/or environmental factors.

Remarkably, we observed that the functional oipA status was significantly associated with gastric cancer, even after adjusting for confounding factors as reported in Colombia [13], where the incidence of gastric cancer is similar to that observed in Ceará state, North-east of Brazil, and unlike in USA [11]. Furthermore, we observed that oipA "on" status was significantly more frequent in the first-degree relatives of gastric cancer patients than in those with gastritis. This finding is a novelty because we are not aware of studies evaluating oipA $H$. pylori virulence marker in such individuals who are at increased risk of gastric cancer that is determined by both bacterial and host factors. It has to be emphasized that first-degree relatives of gastric cancer patients are prone to be colonized by bacteria that circulate within a family. In fact, genetic fingerprint methods have demonstrated genetic homogeneity in the $H$. pylori strains within a family. In a previous study, we have shown that first-degree relatives of gastric cancer patients living in the same Brazilian region were colonized with cagA-positive and vacA more virulent $H$. pylori strains with the same characteristics of those isolated from their parents/siblings with gastric cancer [33].

Evidences that point to the oipA "on" as a gastric cancer risk factor include the ability of the bacterium carrying a functional oipA to attach to the gastric epithelial cells $[12,34]$, to induce inflammation $[12,34]$, apoptosis [34] and toxic effect towards cultured gastric epithelial cell lines [34, 35]. 
H. pylori gastric colonization induces epithelial cells to produce a series of pro-inflammatory and anti-inflammatory cytokines and chemokines; among them IL-8, a potent neutrophil chemotactic and activating peptide [10, 11, 36]. Of interest, Yamaoka et al. have demonstrated that the presence of oipA functional gene is associated with increased IL-8 production by gastric cancer cell line $[10,37]$ and with high concentrations of IL-8 in the antral mucosa [11].

Among the seven oipA sequencing patterns we detected, the $6 \mathrm{CT}$ repeat pattern was the most common oip A "on" status found, in consonance with other studies in Western countries $[11,12,24]$, but different from that observed in Asian countries where the H. pylori strains had less than 5 CT repeats in the oipA gene [27].

In this study, the oipA "on" status could not be discriminated from the other $H$. pylori virulent factors because all of them were highly frequent and closely linked to each other, especially the in frame oip A and cagA virulence factors that have been considered as having a synergistic effect on the pathogenesis induced by $H$. pylori.

Although the sample size had been enough to discriminate the results of high frequency of oipA "on" status between gastric cancer/first-degree relatives of gastric cancer patients and patients with gastritis alone, limitations of our study should be considered. An eventual bias is the small sample size that may preclude associations between oip A "on" status and age and gender. In addition, the small sample size impaired us to evaluate associations between the expression of oipA "on" status and scores of gastritis in the group of first-degree relatives of gastric cancer patients. Because, we evaluated $H$. pylori strains of people living in one of the least developed Brazilian regions, it is possible that these findings differ among the different regions of our country that have marked difference in the prevalence of $H$. pylori-positive status as well as in the prevalence of gastric cancer, which points to the need for further studies on this subject in other geographical regions.

\section{Conclusion}

In conclusion, the oipA "on" status is associated with gastric cancer and with first-degree relatives of gastric cancer patients in North-eastern Brazilian population.

\footnotetext{
Abbreviations

cagA: cytotoxin associated gene; CagA: Cytotoxin associated protein; cagPAl: cytotoxin associated gene pathogenicity island; H. pylori: Helicobacter pylori; oipA: Outer inflammatory gene; OipA: Outer inflammatory protein; PCR: Polymerase chain reaction; vacA: vacuolating cytotoxin gene; VacA: Vacuolating cytotoxin protein
}

\section{Funding}

The study was fundep by Fundação Cearense a Pesquisa (FUNCAP); CNPq (Brazilian National Council of Research) and FAPEMIG (Fundação de Amparo à Pesquisa do Estado de Minas Gerais - Brazil. The funding body had no role in the design of the study, the collection, analysis, and interpretation of data and in writing the manuscript.

\section{Availability of data and materials}

The data that support the findings of this study are available from the corresponding author upon reasonable request.

\section{Authors' contributions}

DMMQ, LLBCB: design and coordination of the study. DMMQ, GAR, LLBCB: Analysis of the data. DMMQ, LLBCB, GAR: preparing the manuscript. MHRB, OGRA, KCSC, ADG: obtained the samples and performed the experiments. All authors read and approved the final manuscript.

\section{Ethics approval and consent to participate}

The study was approved by the Ethical Review Board of the Federal University of Ceará, registration number: 18302214.8.0000.5054 - Fortaleza, Brazil.

The study was performed in accordance with the Declaration of Helsinki. Signed informed consent to participate was obtained from the children (whenever possible) and adolescents and their legal guardians and from adults.

\section{Competing interests}

The authors declare that they have no competing interests.

\section{Publisher's Note}

Springer Nature remains neutral with regard to jurisdictional claims in published maps and institutional affiliations.

\section{Author details}

${ }^{1}$ Clinical Research Unit, University Hospital Walter Cantídio/Department of Internal Medicine, Universidade Federal do Ceará, Fortaleza, Brazil. ${ }^{2}$ Institute of Biomedicine, Universidade Federal do Ceará, Fortaleza, Brazil. ${ }^{3}$ Laboratory of Research in Bacteriology, Faculdade de Medicina, Universidade Federal de Minas Gerais, Av. Alfredo Balena, 190 - Sala 216, Belo Horizonte CEP: 30130-100, Brazil.

Received: 22 August 2018 Accepted: 26 December 2018 Published online: 10 January 2019

\section{References}

1. IARC Helicobacter pylori Working Group. Helicobacter pylori eradication as a strategy for peventing gastric cancer. Lyon: International Agency for Research on Cancer (IARC Working Group Reports, No. 8); 2014. Available from: http://www.iarc.fr/en/publications/pdfs-online/wrk/wrk8/index.php. Accessed 15 Oct 2018

2. Ferlay J, Soerjomataram I, Ervik M. GLOBOCAN 2012 v.1.0, Cancer incidence and mortality worldwide: IARCCancerBase No 11. Lyon: International Agency for Research on Cancer; 2013. http://globocan.iarc. fr. Accessed 15 Oct 2018.

3. INCA, Estimativa 2018. Incidência de cancer no Brasil. http://controlecancer. bvs.br/. Accessed 15 June 2018.

4. Parsonnet J, Friedman GD, Vandersteen DP, Chang $Y$, Vogelman $\mathrm{JH}$, Orentreich $\mathrm{N}$, et al. Helicobacter pylori infection and the risk of gastric carcinoma. N Engl J Med. 1991;325:1127-31.

5. Queiroz DM, Mendes EN, Rocha GA, Oliveira AM, Oliveira CA, Cabral MM, et al. Serological and direct diagnosis of Helicobacter pylori in gastric carcinoma: a case-control study. J Med Microbiol. 1999;48:501-6.

6. Wotherspoon AC, Ortiz-Hidalgo C, Falzon MR, Isaacson PG. Helicobacter pylori-associated gastritis and primary B-cell gastric lymphoma. Lancet. 1991; 338:1175-6.

7. Marshall BJ, Warren JR. Unidentified curved bacilli in the stomach of patients with gastritis and peptic ulceration. Lancet. 1984;1:11-5.

8. Cover TL, Blaser MJ. Helicobacter pylori in health and disease. Gastroenterology. 2009;136:1863-73.

9. Cover TL, Blanke SR. Helicobacter pylori VacA, a paradigm for toxin multifunctionality. Nat Rev Microbiol. 2005;3:320-32.

10. Yamaoka Y, Kwon DH, Graham DY. A M(r) 34,000 proinflammatory outer membrane protein (oipA) of Helicobacter pylori. PNAS. 2000;97:7533-8.

11. Yamaoka Y, Kikuchi S, El Zimaity HMT, Gutierrez O, Osato MS, Graham DY. Importance of Helicobacter pylori oipA in clinical presentation, gastric 
inflammation, and mucosal interleukin 8 production. Gastroenterology. 2002;23:414-24.

12. Yamaoka Y, Kita M, Kodama T, Imamura S, Ohno T, Sawai N, et al. Helicobacter pylori infection in mice: role of outer membrane proteins in colonization and inflammation. Gastroenterology. 2002;123:1992-2004.

13. Yamaoka Y, Ojo O, Fujimoto S, Odenbreit S, Haas R, Gutierrez O, et al. Helicobacter pylori outer membrane proteins and gastroduodenal disease. Gut. 2006;55:775-81.

14. Chiarini A, Calà C, Bonura C, Gullo A, Giuliana G, Peralta S, et al. Prevalence of virulence-associated genotypes of Helicobacter pylori and correlation with severity of gastric pathology in patients from Western Cicily, Italy. Eur I Clin Microbiol Infect Dis. 2008;28:437-46.

15. Gonçalves MHRB, Silva CISM, Braga-Neto MB, Fialho AB, Fialho AM, Queiroz $\mathrm{DM}$, et al. Helicobacter pylori virulence genes detected by string PCR in children from an urban community in northeastern Brazil. J Clin Microbiol. 2013;5:988-9.

16. De Carvalho Costa Cardinali L, Rocha GA, Rocha AM, de Moura SB, de Figueiredo Soares T, Esteves AM, et al. Evaluation of [13C]urea breath test and Helicobacter pylori stool antigen test for diagnosis of H. pylori infection in children from a developing country. J Clin Microbiol. 2003;41:3334-5.

17. Rocha GA, Queiroz DM, Mendes EN, Lage AP, Barbosa AJ. Simple carbolfuchsin staining for showing $C$ pylori and other spiral bacteria in gastric mucosa. J Clin Pathol. 1989:42:1004-5.

18. Dixon MF, Genta RM, Yardley JH, Correa P. Classification and grading of gastritis. The updated Sydney system. International workshop on the histopathology of gastritis, Houston 1994. Am J Surg Pathol. 1996;20: 1161-81.

19. Laurén P. The two histological main types of gastric carcinoma: diffuse and so-called intestinal-type carcinoma. an attempt at a histo-clinical classification. Acta Pathol Microbiol Scand. 1965;64:31-49.

20. Queiroz DM, Bittencourt P, Guerra JB, Rocha AM, Rocha GA, Carvalho AS ILIRN polymorphism and cagA-positive Helicobacter pylori strains increase the risk of duodenal ulcer in children. Pediatr Res. 2005;58:892-6.

21. Ashour AA, Magalhães PP, Mendes EN, Collares GB, de Gusmão VR, Queiroz DM, et al. Distribution of vacA genotypes in Helicobacter pylori strains isolated from Brazilian adult patients with gastritis, duodenal ulcer or gastric carcinoma. FEMS Immunol Med Microbiol. 2002;33:173-8.

22. Atherton JC, Cao P, Peek RM, Tummuru MKR, Blaser MJ, Cover TL. Mosaicism in vacuolating cytotoxin alleles of Helicobacter pylori. association of specific vacA types with cytotoxin production and peptic ulceration. J Biol Chem. 1995;270:17771-7.

23. El-Omar EM, Carrington M, Chow WH, MacColl KE, Bream JH, Young HA, et al. Inlterleukin-1 polymorhisms associated with increased risk of gastric cancer. Nature. 2000;404:398-402.

24. El Omar EM, Ng MT, Hold GL. Polymorphisms in toll-like receptor genes and risk of cancer. Oncogene. 2008;27:244-52.

25. Markovska R, Boyanova L, Yordanov D, Gergova G, Mitov I. Helicobacter pylori oipA genetic diversity and its associations with both disease and cagA, vacA s, $m$, and i alleles among Bulgarian patients. Diag Microbiol Infect Dis. 2011;71:335-40.

26. Torres K, Valderrama E, Sayegh M, Ramírez JL, Chiurillo MA. Study of the oipA genetic diversity and EPIYA motif patterns in cagA-positive Helicobacter pylori strains from Venezuelan patients with chronic gastritis. Microb Pathog. 2014;76:26-32

27. Ando T, Peek RM, Pride D, Levine SM, Takata T, Lee YC, et al. Polymorphisms of Helicobacter pylori HP0638 reflect geographic origin and correlate with cagA status. J Clin Microbiol. 2002:40:239-46.

28. Schmidt HM, Andres S, Nilsson C, Kovach Z, Kaakoush NO, Engstrand L, et al. The cag PAl is intact and functional but HP0521 varies significantly in Helicobacter pylori isolates from Malaysia and Singapore. Eur I Clin Microbiol Infect Dis. 2010;29:439-51.

29. Dossumbekova A, Prinz C, Mages J, Lang R, Kusters JG, Van Vliet AHM, et al. Helicobacter pylori $\mathrm{HopH}$ (OipA) and bacterial pathogenicity: genetic and functional genomic analysis of hopH gene polymorphisms. J Infect Dis. 2006;194:1346-55.

30. Zambon CF, Navaglia F, Basso D, Rugge M, Plebani M. Helicobacter pylori babA2, cagA, and 51 vacA genes work synergistically in causing intestinal metaplasia. J Clin Pathol. 2003;56:287-91.

31. Oleastro M, Santos A, Cordeiro R, Nunes B, Mégraud F, Ménard A. Clinical relevance and diversity of two homologous genes encoding glycosyltransferases in Helicobacter pylori. J Clin Microbiol. 2010;48:2885-91.
32. Yamaoka Y, Reddy R, Graham DY. Helicobacter pylori virulence factor Helicobacter pylori virulence factor: clues about genotype and outcome relationships. J Clin Microbiol. 2010;48:2550-1.

33. Queiroz DM, Silva Cl, Gonçalves MH, Braga-Neto MB, Fialho AB, Fialho AM, et al. BMC Gastroenterol. 2012;12:107. https://doi.org/10.1186/1471-230X-12-10.

34. Teymournejad O, Mobarez AM, Hassan ZM, Abadi ATB. Binding of the Helicobacter pylori OipA causes apoptosis of host cells via modulation of Bax/Bcl-2 levels. Sci Rep Open. 2017;7:e8036.

35. Yamaoka Y, Kita M, Kodama T, Imamura S, Ohno T, Sawai N, Ishimaru A, Imanishi J, Graham DY. Helicobacter pylori infection in mice: role of outer membrane proteins in colonization and inflammation. Gastroenterology. 2002;123:1992-2004

36. Crabtree JE, Wyatt JI, Trejdosiewicz LK, Peichl P, Nichols PH, Ramsay N, et al. Interleukin-8 expression in Helicobacter pylori infected, normal, and neoplastic gastroduodenal mucosa. J Clin Pathol. 1994:47:61-6.

37. Yamaoka Y, Kudo T, Lu H, Casola A, Brasier AR, Graham DY. Role of interferonstimulated responsive element-like element in interleukin-8 promoter in Helicobacter pylori infection. Gastroenterology. 2004;126:1030-43.

\section{Ready to submit your research? Choose BMC and benefit from:}

- fast, convenient online submission

- thorough peer review by experienced researchers in your field

- rapid publication on acceptance

- support for research data, including large and complex data types

- gold Open Access which fosters wider collaboration and increased citations

- maximum visibility for your research: over $100 \mathrm{M}$ website views per year

At BMC, research is always in progress.

Learn more biomedcentral.com/submissions 